\title{
NOTES
}

\section{Synthesis and Properties of Substituted Polyacetylenes Containing a Photosensitive Moiety in the Side Group}

\author{
Kenji WATARI and Hiroaki KouZAi ${ }^{\dagger}$ \\ Department of Applied Material and Life Science, College of Engineering, Kanto Gakuin University, \\ 1-50-1 Mutsuura-higashi, Kanazawa-ku, Yokohama 236-8501, Japan
}

(Received February 28, 2005; Accepted October 20, 2005; Published March 15, 2006)

KEY WORDS Substituted Polyacetylenes / Rh Catalyst / Liquid Crystal / Azobenzene / Photosensitive /

[DOI 10.1295/polymj.38.298]

Molecules which change their material properties or molecular structure in response to external stimuli, especially light, are expected to have application as optical elements, optical storage materials, and the like. Azobenzene reversibly isomerizes between the trans and cis forms when irradiated by ultraviolet or visible light. This photochromic reaction changes the absorption spectrum, refraction index and molecular structure of azobenzene. Many optically functional materials which utilize photochromic reaction of azobenzene have been developed by introducing an azobenzene moiety into the main chain or side chain of a polymer. ${ }^{1,2}$ Conjugated polymers such as polyacetylene have also exhibited a variety of properties such as electrical conductivity, liquid crystal properties and non-linear optical properties. ${ }^{3-5}$ Among these properties, liquid crystal properties such as autonomic orientation and responsiveness to an external field have been utilized in order to improve control of molecular orientation or to improve electrical conductivity. ${ }^{5,6}$ In recent years, liquid crystal substituted polyacetylenes have been synthesized using azobenzene as a mesogen in order to realize liquid crystal conjugated polymers with optical switching functionality, and the liquid crystal properties and optical response of the obtained polymers have been reported. ${ }^{7-9}$ However, a detailed examination of the dependence of the liquid crystal properties on the spacer used for immobilization has hardly been reported. Polymers containing azobenzene moieties in the side chain have attracted much attention because of their unique properties. Azobenzene polymers of high molecular weight have not been obtained. ${ }^{9}$ In this study, we describle a different synthetic design from previous reports, that is, synthesis of acetylene monomers with various oxymethylene chains at their ends using an azo group as a mesogen. These monomers were polymerized with a Rh com- plex catalyst, and properties of the monomers and polymers were investigated.

\section{EXPERIMENTAL}

\section{Materials}

3-Bromo-1-propyne and 5-chloro-1-pentyne were obtained from Tokyo Kasei Kogyo Co., Ltd. All the reagents in monomer synthesis were used as purchased without purification. Triethylamine was dried over $\mathrm{KOH}$ pellets and distilled under reduced pressure. $[\mathrm{Rh}(\mathrm{nbd}) \mathrm{Cl}]_{2}$ was obtained from Aldrich and used as received.

\section{Synthesis of Acetylene Monomers}

Figure 1 shows the synthetic route to the acetylene monomers ( $\mathbf{1}$ or $\mathbf{2}$ ). An azobenzene derivative $\mathbf{3}$ was synthesized by azo coupling of various anilines and phenols. Acetylene monomers $\mathbf{1}$ and $\mathbf{2}$ were synthesized by the reaction between the azobenzene derivative 3 and 5-chloro-1-pentyne or 3-bromo-1-propyne in the presence of $\mathrm{K}_{2} \mathrm{CO}_{3}$ with THF as a solvent. The acetylene monomers $\mathbf{1}$ and $\mathbf{2}$ were obtained as a yellow powder in 35-60\% yield. Compound $\mathbf{1 b}$ was synthesized by modifying the literature method, ${ }^{8}$ and 5-chloro-1-pentyne was used as a starting material. The data were as follows. Yield: $60 \%$, yellow powder. $\mathrm{IR}(\mathrm{KBr}): 3200(\equiv \mathrm{C}-\mathrm{H}), 2100(-\mathrm{C} \equiv \mathrm{C}-), 670(\equiv \mathrm{C}-\mathrm{H})$ $\mathrm{cm}^{-1} .{ }^{1} \mathrm{H} \mathrm{NMR}\left(\mathrm{CDCl}_{3}\right) \delta 1.45\left(t,-\mathrm{C}_{3}, 3 \mathrm{H}, J=\right.$ $6.95 \mathrm{~Hz}), 1.98\left(t,-\mathrm{CH}_{2}-\mathrm{CH}_{2}-\mathrm{CH}_{2}-\mathrm{O}-, 2 \mathrm{H}, J=2.65\right.$ $\mathrm{Hz}), 2.02(s, \underline{\mathrm{H}}-\mathrm{C} \equiv \mathrm{C}-, 1 \mathrm{H}), 2.07\left(m, \mathrm{H}-\mathrm{C} \equiv \mathrm{C}-\mathrm{C}_{\mathrm{H}_{2}}-\right.$, $2 \mathrm{H}), 4.10\left(t,-\mathrm{O}-\mathrm{CH}_{2}-\mathrm{CH}_{3}, 2 \mathrm{H}, J=6.95 \mathrm{~Hz}\right), 4.14(t$, $\left.-\mathrm{CH}_{2}-\mathrm{C}_{2}-\mathrm{O}-, 2 \mathrm{H}, J=6.04 \mathrm{~Hz}\right), 6.97,7.86(d, \mathrm{Ar}-$ $\underline{\mathrm{H}}, 4 \mathrm{H}, J=8.78 \mathrm{~Hz}) \mathrm{ppm} .{ }^{13} \mathrm{C} \mathrm{NMR}\left(\mathrm{CDCl}_{3}\right) \delta 13.8$, 19.2, 31.2, 65.1, 68.0, 74.7, 84.0, 114.5, 124.3, 144.7, $161.1 \mathrm{ppm} .1 \mathrm{a},{ }^{1} \mathrm{H}$ NMR $\left(\mathrm{CDCl}_{3}\right) \delta 1.52\left(t,-\mathrm{C}_{2}-\mathrm{C} \equiv\right.$ $\mathrm{C}-\mathrm{H}, 2 \mathrm{H}, J=7.51 \mathrm{~Hz}), 1.80\left(t,-\mathrm{CH}_{2}-\mathrm{C}_{2}-\mathrm{CH}_{2}-\mathrm{O}-\right.$,

${ }^{\dagger}$ To whom correspondence should be addressed (Tel: +81-45-786-7155, Fax: +81-45-786-7098, E-mail: kouzai@kanto-gakuin.ac.jp). 


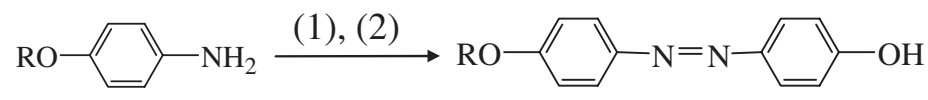

3

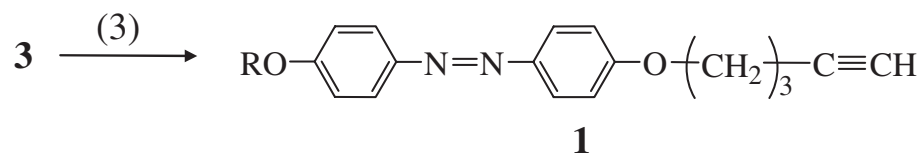

1a: $\mathrm{R}=\mathrm{CH}_{3}, \mathbf{1 b}: \mathrm{R}=\mathrm{C}_{2} \mathrm{H}_{5}, \mathbf{1 c}: \mathrm{R}=\mathrm{C}_{4} \mathrm{H}_{9}$

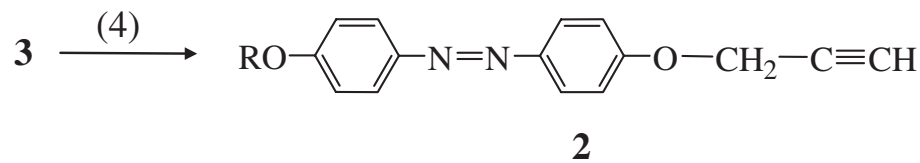

2a: $\mathrm{R}=\mathrm{CH}_{3}, \mathbf{2 b}: \mathrm{R}=\mathrm{C}_{2} \mathrm{H}_{5}, \mathbf{2 c}: \mathrm{R}=\mathrm{C}_{4} \mathrm{H}_{9}$

Figure 1. The synthetic route of acetylene monomers. Reagents and condition: (1) $\mathrm{NaNO}_{2}, \mathrm{H}_{2} \mathrm{O} ; 5{ }^{\circ} \mathrm{C}, 2 \mathrm{~h}$. (2) $\mathrm{C}_{6} \mathrm{H}_{5} \mathrm{OH}, \mathrm{NaOH}_{2} \mathrm{H}_{2} \mathrm{O}$, $5{ }^{\circ} \mathrm{C}, 2 \mathrm{~h}$. (3) 5-chloro-1-pentyne, $\mathrm{K}_{2} \mathrm{CO}_{3}$, THF, $70^{\circ} \mathrm{C}, 48 \mathrm{~h}$. (4) 3-bromo-1-propyne, $\mathrm{K}_{2} \mathrm{CO}_{3}, \mathrm{THF}, 70{ }^{\circ} \mathrm{C}, 24 \mathrm{~h}$.

$2 \mathrm{H}, J=7.59 \mathrm{~Hz}), 2.55(s, \underline{\mathrm{H}}-\mathrm{C} \equiv \mathrm{C}-, 1 \mathrm{H}), 4.03(t,-\mathrm{O}-$ $\left.\mathrm{C}_{2}-, 2 \mathrm{H}, J=6.50 \mathrm{~Hz}\right), 4.76\left(t,-\mathrm{O}-\mathrm{C}_{3}, 3 \mathrm{H}, J=\right.$ $2.56 \mathrm{~Hz}), 7.07,7.87(d, \mathrm{Ar}-\underline{\mathrm{H}}, 4 \mathrm{H}, J=6.95,6.95 \mathrm{~Hz})$ ppm. 1c, ${ }^{1} \mathrm{H}$ NMR $\left(\mathrm{CDCl}_{3}\right) \delta 0.93\left(t, \mathrm{CH}_{3}-, 3 \mathrm{H}, J=\right.$ $3.48 \mathrm{~Hz}), 1.35\left(t, \mathrm{CH}_{3}-\mathrm{CH}_{2}-\mathrm{CH}_{2}-, 2 \mathrm{H}, J=7.23 \mathrm{~Hz}\right)$, $1.48\left(t,-\mathrm{CH}_{2}-\mathrm{CH}_{2}-\mathrm{CH}_{2}-\mathrm{O}-, 2 \mathrm{H}, J=6.40 \mathrm{~Hz}\right), 1.85$ $\left(t, \mathrm{H}-\mathrm{C} \equiv \mathrm{C}-\mathrm{C}_{2}-, 2 \mathrm{H}, J=7.59 \mathrm{~Hz}\right), 3.21(s, \underline{\mathrm{H}}-\mathrm{C} \equiv$ $\mathrm{C}-, 1 \mathrm{H}), 4.04\left(t,-\mathrm{CH}_{2}-\mathrm{CH}_{2}-\mathrm{O}-, 4 \mathrm{H}, J=6.59 \mathrm{~Hz}\right)$, $7.00,7.91(d, \operatorname{Ar}-\underline{\mathrm{H}}, 4 \mathrm{H}, J=2.10,2.10 \mathrm{~Hz})$ ppm. $2 \mathbf{a}$, ${ }^{1} \mathrm{H}$ NMR $\left(\mathrm{CDCl}_{3}\right) \delta 2.26\left(t, \mathrm{CH}_{3}-\mathrm{O}-, 3 \mathrm{H}, J=3.57\right.$ $\mathrm{Hz}), 3.88(s, \underline{\mathrm{H}}-\mathrm{C} \equiv \mathrm{C}-, 1 \mathrm{H}), 4.76\left(d,-\mathrm{O}-\mathrm{C}_{2}-\mathrm{C} \equiv\right.$ $\mathrm{C}-\mathrm{H}, 2 \mathrm{H}, J=2.38 \mathrm{~Hz}), 7.08,7.88(d, \mathrm{Ar}-\underline{\mathrm{H}}, 4 \mathrm{H}, J=$ $6.86,8.97 \mathrm{~Hz}) \mathrm{ppm}$.

\section{Polymerization}

All the polymerizations were carried out in a glass tube equipped with a three-way stopcock under nitrogen. The polymerization conditions were as follows: A solution of $\left[\mathrm{Rh}(\mathrm{nbd}) \mathrm{Cl}_{2}\right.$ and triethylamine in distilled dichloromethane in a solvent was kept at $30{ }^{\circ} \mathrm{C}$ for $3 \mathrm{~h}$ in a glass tube under nitrogen. ${ }^{10}$ The polymers were isolated by precipitation in a large amount of ethanol under stirring. The precipitate was collected by filtration and dried under vacuum. Poly 1b, ${ }^{1} \mathrm{H}$ NMR $\left(\mathrm{CDCl}_{3}\right) \delta 1.45\left(m,-\mathrm{CH}_{3}, 3 \mathrm{H}\right)$, $2.17\left(t,-\mathrm{CH}_{2}-\mathrm{CH}_{2}-\mathrm{CH}_{2}-\mathrm{O}-, 2 \mathrm{H}\right), 2.81(m, \mathrm{H}-\mathrm{C} \equiv$ $\left.\mathrm{C}-\mathrm{CH}_{2}-, 2 \mathrm{H}\right), 4.11\left(t,-\mathrm{O}-\mathrm{CH}_{2}-\mathrm{CH}_{3}, 2 \mathrm{H}\right), 4.14(t$, $\left.-\mathrm{CH}_{2}-\mathrm{CH}_{2}-\mathrm{O}-, 2 \mathrm{H}\right), 6.96,7.83$ (d, Ar- $\left.\underline{\mathrm{H}}, 4 \mathrm{H}\right) \mathrm{ppm}$. Anal. Found: C, 74.21; H, 6.44; N, 8.73\%. Calculated for $\left(\mathrm{C}_{19} \mathrm{H}_{20} \mathrm{~N}_{2} \mathrm{O}_{2}\right)_{n}: \mathrm{C}, 73.99 ; \mathrm{H}, 6.55 ; \mathrm{N}, 9.08 \%$. Poly 1a, ${ }^{1} \mathrm{H}$ NMR $\left(\mathrm{CDCl}_{3}\right) \delta 1.55\left(t,-\mathrm{C}_{2}-\mathrm{C} \equiv \mathrm{C}-\mathrm{H}, 2 \mathrm{H}\right)$, $1.80\left(t,-\mathrm{CH}_{2}-\mathrm{CH}_{2}-\mathrm{CH}_{2}-\mathrm{O}-, 2 \mathrm{H}\right), 4.03\left(t,-\mathrm{O}-\mathrm{CH}_{2}-\right.$, $2 \mathrm{H}), 4.72\left(t,-\mathrm{O}-\mathrm{C}_{3}, 3 \mathrm{H}\right), 7.05,7.87(d, \mathrm{Ar}-\underline{\mathrm{H}}, 4 \mathrm{H})$ ppm. Poly 1c, ${ }^{1} \mathrm{H}$ NMR $\left(\mathrm{CDCl}_{3}\right) \delta 0.93\left(t, \mathrm{CH}_{3}-\right.$, $3 \mathrm{H}), 1.35\left(t, \mathrm{CH}_{3}-\mathrm{CH}_{2}-, 2 \mathrm{H}\right), 1.48\left(t,-\mathrm{CH}_{2}-\mathrm{CH}_{2}-\right.$ $\left.\mathrm{CH}_{2}-\mathrm{O}-, 2 \mathrm{H}\right), 1.86\left(t, \mathrm{H}-\mathrm{C} \equiv \mathrm{C}-\mathrm{CH}_{2}-, 2 \mathrm{H}\right), 4.00(t$, $\left.-\mathrm{CH}_{2}-\mathrm{C}_{2}-\mathrm{O}-, 4 \mathrm{H}\right), 7.00,7.91$ (d, Ar- $\left.\underline{\mathrm{H}}, 4 \mathrm{H}\right) \mathrm{ppm}$.
Poly 2a, ${ }^{1} \mathrm{H}$ NMR $\left(\mathrm{CDCl}_{3}\right) \delta 2.30\left(t, \mathrm{C}_{3}-\mathrm{O}-, 3 \mathrm{H}\right)$, $4.81\left(d,-\mathrm{O}-\mathrm{C}_{2}-\mathrm{C} \equiv \mathrm{C}-\mathrm{H}, 2 \mathrm{H}\right), 7.13,7.90(d$, Ar- $\underline{\mathrm{H}}$, 4H) ppm.

\section{Measurement}

Infrared absorption spectra (FT/IR) were measured using a JASCO FT/IR-615 spectrometer. Nuclear magnetic resonance spectra $\left({ }^{1} \mathrm{H}\right.$ NMR) in solution were recorded on a Varian Mercury plus $400 \mathrm{MHz}$ spectrometer (Varian Technologies Co., Ltd., Japan). Elemental analysis was carried out at the Kyoto University Elemental Analysis Center. The molecular weight of the polymers was determined by gel permeation chromatography (GPC) on a TOSOH HLC8220 , with polystyrene as a calibrating standard. The phase transition temperature of the acetylene monomers was measured by differential scanning calorimetry (DSC, programming rate $5-10 \mathrm{~K} \cdot \mathrm{min}^{-1}$ ) on a Rigaku Thermoplus DSC 8230 and the liquid crystal phase was observed by polarizing microscope on a OLYMPUS BX51. Absorption spectra were obtained on a JASCO Ubesut-50 spectrometer. The samples were irradiated by $500 \mathrm{~W}$ super high-pressure mercury lamp through appropriate optical glass filters such as the UV-D33S filter for UV light irradiation. Thermogravimetric analyses (TGA) were conducted in air with a Rigaku Thermoplus TG 8120.

\section{RESULTS AND DISCUSSION}

The structures of the obtained acetylene monomers were confirmed by FT/IR and ${ }^{1} \mathrm{H}$ NMR. Transition temperatures of the synthesized acetylene monomers are shown in Table I. As shown in Table I, for $\mathbf{1 b}$ and 1c, the phase transition could be observed during both raising and lowering of the temperature by DSC, and an optical pattern indicating the liquid crystal 
Table I. Transition temperature of the synthesized compounds

\begin{tabular}{ccc}
\hline \multirow{2}{*}{ Compounds } & \multicolumn{2}{c}{ Phase transition temperatures $\left({ }^{\circ} \mathrm{C}\right)^{\mathrm{a}}$} \\
\cline { 2 - 3 } & First cooling & Second heating \\
\hline 1a & i $104 \mathrm{Cr}$ & Cr $123 \mathrm{i}$ \\
1b & i $96 \mathrm{~N} 75 \mathrm{Cr}$ & Cr $103 \mathrm{~N} 115 \mathrm{i}$ \\
$1 \mathrm{c}$ & i $93 \mathrm{~N} 68 \mathrm{Cr}$ & $\mathrm{Cr} 88 \mathrm{~N} 101 \mathrm{i}$ \\
$2 \mathrm{a}$ & i $140 \mathrm{Cr}$ & $\mathrm{Cr} 156 \mathrm{i}$ \\
2b & i $112 \mathrm{Cr}$ & $\mathrm{Cr} 123 \mathrm{i}$ \\
2c & i $94 \mathrm{Cr}$ & Cr $105 \mathrm{i}$ \\
\hline
\end{tabular}

a Abbreviation: $\mathrm{Cr}=$ crystal, $\mathrm{N}=$ nematic, $\mathrm{i}=$ isotropic.

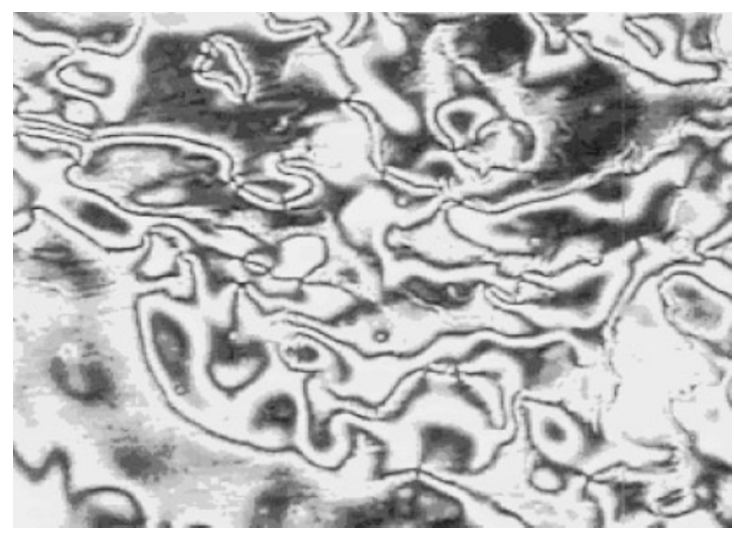

Figure 2. Polarizing optical photomicrograph of $\mathbf{1 b}$ at $105^{\circ} \mathrm{C}$.

Table II. Synthetic results of polymers

\begin{tabular}{cllccccc}
\hline \multirow{2}{*}{ Monomer } & \multicolumn{2}{c}{ Reaction Condition ${ }^{\mathrm{a}}$} & \multirow{2}{*}{$\begin{array}{c}\text { Yield } \\
(\%)\end{array}$} & $M_{\mathrm{n}} / 10^{4 \mathrm{~b}}$ & $M_{\mathrm{w}} / 10^{4 \mathrm{~b}}$ & $M_{\mathrm{w}} / M_{\mathrm{n}}{ }^{\mathrm{b}}$ \\
\cline { 2 - 3 } & \multicolumn{2}{c}{ Catalyst } & Solvent & & & \\
\hline $1 \mathrm{a}$ & {$[\mathrm{Rh}(\mathrm{nbd}) \mathrm{Cl}]_{2}$-TEA } & $\mathrm{CH}_{2} \mathrm{Cl}_{2}$ & 83 & 0.8 & 1.5 & 1.9 \\
$1 \mathrm{~b}$ & {$[\mathrm{Rh}(\mathrm{nbd}) \mathrm{Cl}]_{2}$-TEA } & $\mathrm{CH}_{2} \mathrm{Cl}_{2}$ & 91 & 1.3 & 2.8 & 2.2 \\
$1 \mathrm{c}$ & {$[\mathrm{Rh}(\mathrm{nbd}) \mathrm{Cl}]_{2}$-TEA } & $\mathrm{CH}_{2} \mathrm{Cl}_{2}$ & 79 & 0.9 & 1.7 & 1.9 \\
$2 \mathrm{a}$ & {$[\mathrm{Rh}(\mathrm{nbd}) \mathrm{Cl}]_{2}$-TEA } & $\mathrm{CH}_{2} \mathrm{Cl}_{2}$ & 79 & 0.7 & 1.5 & 2.1 \\
$2 \mathrm{~b}$ & {$[\mathrm{Rh}(\mathrm{nbd}) \mathrm{Cl}]_{2}$-TEA } & $\mathrm{CH}_{2} \mathrm{Cl}_{2}$ & 74 & 0.8 & 1.6 & 2.0 \\
$2 \mathrm{c}$ & {$[\mathrm{Rh}(\mathrm{nbd}) \mathrm{Cl}]_{2}$-TEA } & $\mathrm{CH}_{2} \mathrm{Cl}_{2}$ & 82 & 1.1 & 2.5 & 2.3 \\
\hline
\end{tabular}

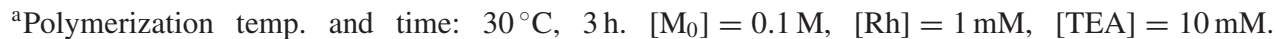

${ }^{\mathrm{b}}$ Determined by GPC in THF based on polystyrene standards.

phase could be observed using the polarizing microscope. In this case, 1c containing an oxymethylene chain with a longer end was found to exist in the liquid crystal phase over a wider temperature range, and thus its phase structure was more stable than that of 1b. Figure 2 shows a polarizing optical microphotograph of a sample of $\mathbf{1 b}$ on heating at $105^{\circ} \mathrm{C}$. The mesophase was observed to be of nematic schlieren texture. On the other hand, for $\mathbf{1 a}$ and $\mathbf{2}$, no phase transition or optical pattern was observed. This suggests that the length of the methylene chain between the acetylene site and the mesogen as well as the length of the oxymethylene end chain largely determine whether the liquid crystal phase is expressed.

Table II shows the results of polymer synthesis. All polymers were obtained at a yield of around $50 \%$ as brown solids. The molecular weights were measured by GPC (using the polystyrene standard). All the polymers possessed moderate molecular weights $\left(M_{\mathrm{n}}=\right.$ 7000-13000), and their polydispersities $\left(M_{\mathrm{w}} / M_{\mathrm{n}}\right)$ were in the range of $c a$. 1.9-2.3. Thus, it is concluded that these monomers give polymers having relatively high molecular weight in good yields. These results are somewhat better than these of polyacetylenes by Rh catalysts. ${ }^{9}$ The characteristic absorptions of $\equiv \mathrm{C}-\mathrm{H}$ $\left(3200 \mathrm{~cm}^{-1}\right)$ and $\mathrm{C} \equiv \mathrm{C}\left(2100 \mathrm{~cm}^{-1}\right)$ stretchings seen in the monomer spectra have completely disappeared in the polymer spectra. The obtained polymers were soluble in organic solvents such as toluene, chloroform and THF. It is considered that the signal at 6.1 ppm corresponds to the cis structure can be observed, and that the cis structure forms selectively in $\mathbf{1 b}$. However, a liquid crystalline phase could not be confirmed from either DSC or the polarizing optical microphotograph of the obtained polymers. The liquid crystalline phase is considered to be more likely to occur for the trans form than the cis form. It can be supposed that the polymer principal chain is remarkably stiff, and the flexibility of the molecules largely lost.

Figures 3 and 4 show changes in the UV-vis spectra of polymer 1b in THF during irradiation of ultraviolet and visible light. An absorption peak near 350 $\mathrm{nm}$ due to the trans form of the azo group in the side chain and an absorption peak near $240 \mathrm{~nm}$ due to conjugated double bonds could be confirmed. When polymer $\mathbf{1 b}$ in THF was irradiated with ultraviolet light $(350-400 \mathrm{~nm})$ for a set time, absorption due to the trans form of the azo group $(350 \mathrm{~nm})$ rapidly decreased and a new absorption near $440 \mathrm{~nm}$, which is derived from the cis form, was observed (Figure 3). In subsequent irradiation of the polymer with visible light $(>420 \mathrm{~nm})$, the absorption due to the cis form $(440 \mathrm{~nm})$ decreased and the absorption due to the trans form $(350 \mathrm{~nm})$ increased (Figure 4$)$. The absorption intensity at $240 \mathrm{~nm}$, an absorption corresponding to a disubstituted phenylene ring, decreased in intensi- 


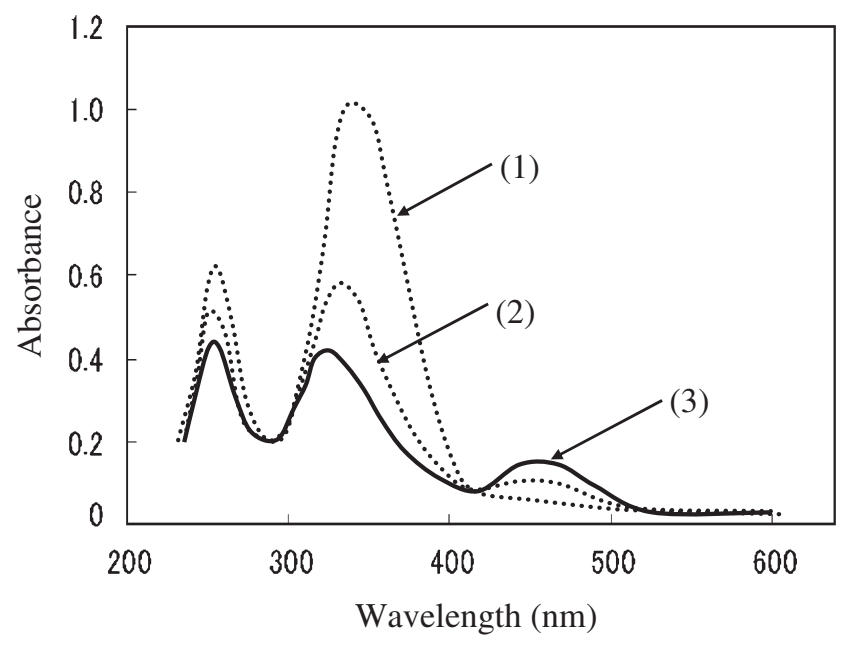

Figure 3. UV-vis spectra of polymer $2 \mathbf{b}$ in THF (1) before, (2) after UV irradiation at $300-400 \mathrm{~nm}$ for $5 \mathrm{~min}$, and (3) after UV irradiation for $60 \mathrm{~min}$.

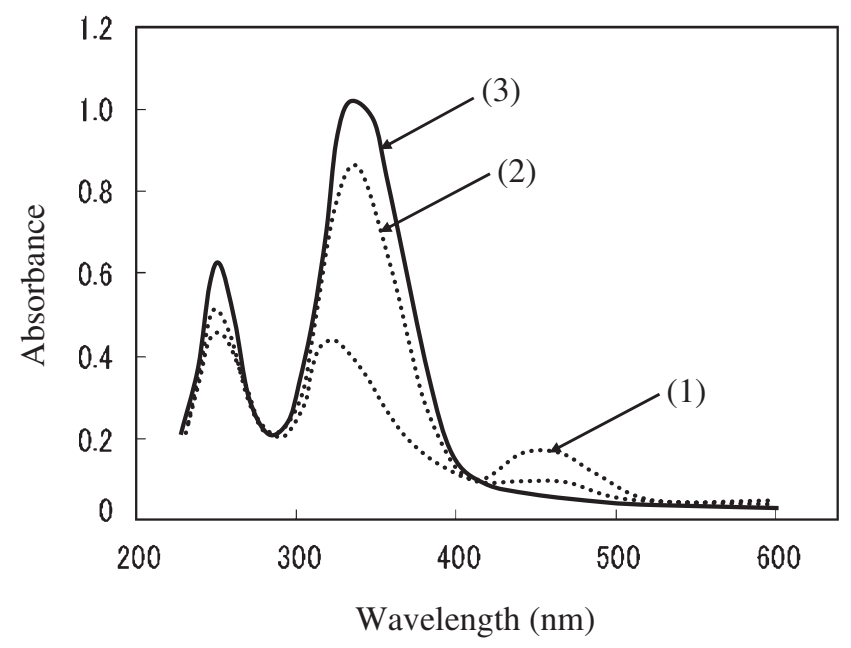

Figure 4. UV-vis spectra of polymer $\mathbf{2 b}$ in THF (1) before, (2) after irradiation at $>420 \mathrm{~nm}$ for $5 \mathrm{~min}$, and (3) after irradiation for $60 \mathrm{~min}$.

ty upon the UV light irradiation. These results suggest that the azo group in the side chain of the substituted polyacetylene isomerizes between the trans and cis forms when irradiated with ultraviolet or visible light. Similar changes in the peaks of UV-vis absorption spectra were confirmed for other polymers. From TGA measurement, it was shown that all polymers had high thermal stability with the temperature of initial weight loss ranging from 320 to $410{ }^{\circ} \mathrm{C}$.

In conclusion, novel acetylene-substituted monomers having various oxymethylene chains at their ends were synthesized using an azo group as a mesogen. The monomers were polymerized using the $\mathrm{Rh}$ catalyst $[\mathrm{Rh}(\mathrm{nbd}) \mathrm{Cl}]_{2}$ to obtain polymers on the order of tens of thousands. All polymers were soluble in organic solvents such as toluene, chloroform and tetrahydrofuran. The obtained polymers were confirmed to exhibit photoisomerization between the trans and cis forms when irradiated by ultraviolet or visible light.

Acknowledgment. This research was supported by MEXT. HAITEKU(2005). The authors are grateful to Professor K. Matsui, Kanto Gakuin University, Yokohama, Japan, for obtaining UV-vis absorption spectra of the samples.

\section{REFERENCES}

1. O. Tsutsumi, T. Shiono, T. Ikeda, and G. Galli, J. Phys. Chem. B, 101, 1332 (1997).

2. O. Tsutsumi, T. Kitsunai, A. Kanazawa, T. Shiono, and T. Ikeda, Macromolecules, 31, 355 (1998).

3. T. Masuda, K. Hasegawa, and T. Higashimura, Macromolecules, 7, 728 (1974).

4. D. Neher, A. Wolf, C. Bubeck, and G. Wegner, Chem. Phys. Lett., 163, 116 (1989).

5. S. Y. Oh, K. Akagi, and H. Shirakawa, Macromolecules, 26, 6203 (1993).

6. K. Akagi, H. Goto, Y. Kadokura, H. Shirakawa, S. Y. Oh, and K. Araya, Synth. Met., 69, 13 (1995).

7. K. Akagi, H. Goto, S. Fujita, and H. Shirakawa, J. Photopolym. Sci. Technol., 10, 233 (1997).

8. S. Y. Oh, S. M. Hong, and S. I. Oh, Mol. Cryst. Liq. Cryst., 295, 105 (1997).

9. S. I. Oh, D. J. Byun, and S. Y. Oh, Mol. Cryst. Liq. Cryst., 316, 333 (1998).

10. M. Tabata, T. Sone, and Y. Sadahiro, Macromol. Chem. Phys., 200, 265 (1999). 